\title{
EFFECT OF TRANSCUTANEOUS ELECTRICAL NERVE STIMULATION (TENS) ON HORMONE PROFILES IN SUBJECTS WITH PRIMARY DYSMENORRHOEA - PRELIMINARY STUDY
}

\author{
*BA Tella, *AJ Olisah, *SRA Akinbo, **GO Ajayi, ***D Alamu and ***B Oshundiya \\ Departments of *Physiotherapy, **Obstetric and Gynaecology, ***Prenatal diagnosis and Therapy \\ Centre, College of Medicine, University of Lagos. P.M.B 12003, Surulere, Lagos. \\ Corresponding Author \\ BA Tella \\ adedemi@yahoo.com
}

\begin{abstract}
SUMMARY
Background \& Objective: Primary dysmenorrhoea (PD) is the occurrence of painful menstrual cramps of uterine origin which occurs in the absence of any underlying disease. The objective of this study was to evaluate the effect of TENS on the hormones; cortisol and prolactin in individual with PD.

Methods: Plasma levels of cortisol and prolactin were studied in twenty-one (21) subjects with mean age of $23 \pm 2$ years by obtaining blood sample from each subject, pre-and post-TENS therapy on the first day of menstruation. Visual Analogue Scale (VAS) was used to assess the pre-and post-treatment pain intensity. The TENS unit was applied for a duration of 30 minutes.

Results: The paired t-test showed that there was an overall reduction in the mean cortisol and prolactin from pre treatment values of $28.45 \mu \mathrm{g} / \mathrm{dl} \pm 5.27$ and $56.81 \mathrm{ng} / \mathrm{ml} \pm 31.86$ to post treatment values of $27.33 \mu \mathrm{g} / \mathrm{dl} \pm 5.13$ and $53.23 \mathrm{ng} / \mathrm{ml} \pm 37.63$ respectively. However these differences were not statistically significant $(\mathrm{P}>0.05)$. Pain intensity was significantly reduced comparing pre and post treatment VAS scores.

Conclusion: The probable mechanism by which TENS effects alteration in cortisol and prolactin levels and pain reduction in PD might be through the opioid-modulating analgesia system, which releases B-endorphins and other endogenous opiates in response to pain. This is because there is close relationship between B-endorphin, cortisol and neurons, which secrete dopamine into the hypothalamic-pituitary-portal system. However this study gives further evidence that women with PD have disturbed hormonal profiles.
\end{abstract}

KEY WORDS: Primary dysmenorrhoea, TENS, Cortisol, Prolactin.

\section{INTRODUCTION}

Dysmenorrhoea is a pain occurring at or about the time of the menses. It can be classified as primary or secondary. Primary dysmenorrhoea (PD) is the occurrence of painful menstrual cramps of uterine origin which occurs in the absence of any obvious underlying disease (Akin et al, 2001; Proctor et al, 2004). The pains are usually located in the suprapubic area radiating to the back, sacrum or inner thighs. The pain may accompany the beginning of menstrual flow or precede it by a few hours. PD is known to manifest clinical features such as, nausea, vomiting, diarrhoea, headache and tiredness (Dawood and Ramos, 1990; Smith, 1993).

Secondary or acquired dysmenorrhoea is pain occurring when there has been little or no pain until some disease has occurred in the pelvis. It is commonly associated with pelvis inflammation, endomentritis and fibroids (Akin et al, 2001). Dysmenorrhoea affects $40 \%$ to $70 \%$ of women of reproductive age. It is one of the most frequent causes of absenteeism from work and school (Andersch and Milson, 1982). The high prevalence and enormous medical, social and economic consequences of dysmenorrhoea are therefore substantial. This has led to numerous studies of its pathophysiology and treatment (Li, 1998; Zhang et al, 1998).

While the true cause of $P D$ remains uncertain, various hormonal activities have been implicated as causative factors. The increase in prostaglandins in the endometrium, following the fall in progesterone in the late luteal phase of the menstrual cycle which results in increased myometrial tone and excessive uterine contraction have been implicated (Akin et al, 2001). Women with severe PD have been shown to have higher plasma concentrations of arginine vasopressin (AVP), than healthy subjects on the first day of menstruation (Stromberg et al, 1981). 
Prolactin, a stress hormone, is secreted by the anterior pituitary gland and regulated by the action of dopamine (Stromberg et al, 1981). Prolactin has been suggested to play an essential role in the menstrual cycle as it has been linked to a number of menstrual dysfunctions (De-Cree, 1989). Normal range of prolactin in premenopausal women is $1.2-19.5 \mathrm{ng} / \mathrm{ml}$ (Ganong, 2001). Another stress hormone is cortisol, synthesized by the adrenal cortex and regulated by adrenocorticotropic hormone (ACTH) which is an anterior pituitary hormone (Ganong, 2001). The concentration of cortisol varies with time of day and, in women, with phase of menstruation (Kaplan et al, 1994). According to Orth et al, (1992) and Kaplan et al, (1994), highest concentrations range from $10-27 \mathrm{ug} / \mathrm{dL}$ and are seen in the early morning, within the usual time of wakening. Plasma cortisol concentration ranges from 3-10ug/dL at 4pm and lowest levels, less than $5 u g / d L$ are observed an hour after the usual time of sleep (Gannong, 2001).

Different methods with varying side effects have been employed in the management of PD. In the 1960s oral contraceptives were commonly used (Menaker et al, 1962; Mathews et al, 1968). Oral contraceptives reduce the pain of $P D$ by reducing menstrual fluid prostaglandins, as a result of an overall decrease in menstrual fluid volume (Chan and Dawood, 1980). The efficacy of oral contraceptives in the treatment of PD is well recognized and documented, however they have adverse effect on the gastrointestinal tract on prolong administration (Langrick et al, 1989).

Since the 1970s, oral contraceptives have given way to non-steroidal anti-inflammatory drugs (NSAIDs) in the management of PD. However, it has been reported that only twothirds of dysmenorrhoeic women responded positively to NSAIDs, and are known to also have associated side effects (Henzl et al, 1998; Langrick et al, 1989). Previous research studies have showed that prostaglandin was implicated in the pathogenesis of PD (Flower and Vane, 1974; Pulkkinen, 1979)). NSAIDs act by suppressing menstrual fluid prostaglandins through enzymatic inhibition of prostaglandin.

In the 1980s a number of studies involving acupuncture on PD was carried out (Yuqin, 1994; Manheimer and Whalen, 1985; Lundeberg et al, 1985). A preliminary trial reported that $86 \%$ of dysmenorrhoeic women treated with acupuncture had complete relief of pain for three consecutive menstrual periods (Manheimer and Whalen, 1985). The use of acupuncture-like TENS was compared with conventional TENS and there was significant pain relief in both forms (Manheimer and Whalen, 1985). The use of high-frequency TENS $(100 \mathrm{~Hz})$, low frequency TENS (2Hz) and placebo-TENS was investigated in a group of dysmenorrhoeic patients. It was discovered that the patients treated with high, and low frequency TENS obtained pain relief exceeding $50 \%$ of its original intensity but in some of the low frequency subjects, the pain relief was counteracted by naxolone, a relatively pure opiate antagonist (Lundeberg et al, 1985). A comparative study on effects of acupuncture-like TENS and placebo pill on PD revealed an average pain relief of 50\% post-treatment (Lewers et al, 1989).

While different methods - with varying side effects and clinical outcome - have been employed in the management of PD, TENS has been reported to be a safe and effective nonpharmacological means of treating PD (Kaplan et al, 1994). Also hormonal imbalance has been linked as contributing factors to the pain experienced during menstruation (Baker et al, 1999). This study was therefore conducted to evaluate the effect of TENS on hormones (prolactin and cortisol) profile amongst University undergraduate with PD.

\section{METHODS}

Twenty one female undergraduate subjects, age 18 - 26 years participated in this study. The local Ethics Committee approved the study protocol and all patients gave written informed consent.

Subjects with regular menstrual periods and those without prior TENS treatment were included, while subjects on regular pain relieving drugs were excluded. Subjects were assessed by history and a detailed physical examination by a physician and a physiotherapist before inclusion in the study.

\section{INSTRUMENTATION}

- Transcutaneous Electrical Nerve Stimulation (TENS) unit

- Visual Analogue Scale (VAS)

- DSL-10-2000 Active ${ }^{\circledR}$ Cortisol EIA Kit

- ELISA Prolactin Kit

- Centrifuge

- Vacutainer bottles

- Sterilized needles and syringes

- Methylated Spirit and cotton wools

\section{Experimental Procedure}

An experimental study design made up of one group pretest and post test design was used. All the subjects completed the questionnaires and were briefed on the experimental procedure prior to the commencement of the study. On the first day of menstruation between 8.00 AM and 10.00AM, each subject indicated her pain level on the Visual Analogue Scale (VAS). Subject was then placed on supine position on a plinth, for the collection of blood sample on the median 
cubital vein of the subject's arm and transferred to labeled vacutainer bottle. This serves as the pre treatment blood sample.

Following this procedure TENS was then administered with two pairs of electrodes placed around the painful region which is the suprapubic area in all the subjects. A pair of the adhesive electrodes was placed $10 \mathrm{~cm}$ from the umbilicus on either side, the second pair placed on either side of the pubic symphysis close to each anterior superior iliac spine (Lundeberg et $a l, 1985)$. High frequency TENS was applied at $100 \mathrm{~Hz}$ and $250 \mu$ s of pulse rate and pulse width respectively, the intensity was adjusted to a tolerable level of stimulation. Treatment lasted for 30 minutes. TENS application was done in supine lying position. At the termination of TENS therapy, the subjects' pain level was reassessed and a second blood sample (post treatment) obtained. All the blood samples (pre and post TENS) collected were subjected to laboratory analysis to determine the cortisol and prolactin levels in each subject using the ELISA method (Chan and Dawood, 1980).

\section{Statistical Analysis}

The demographic data of the subjects were summarized using the descriptive statistics of mean and standard deviation. Student t-test was used to determine if there was any significant difference in the pre-and post TENS prolactin and cortisol values.

Wilcoxon Signed Ranks Test was used to determine if there was any significance difference in the pain levels of the subjects preand post TENS therapy.

\section{RESULTS}

A total of 21 ladies of ages 18 to 26 years (mean age 23 \pm 2 ) with PD participated in the study. Previous methods of dysmenorrhoea pain relief used by the subjects indicate that $61.90 \%$ of the subjects commonly used analgesic drugs, $38.10 \%$ used nothing at all while none has tried the use of TENS previously.

Table 1 shows the analysis of significant difference between the pre-and posts TENS therapy Cortisol and Prolactin levels. There was a slight reduction in the mean Cortisol level from $28.45 \mu \mathrm{g} / \mathrm{dl} \pm 5.27$ to $27.33 \mu \mathrm{g} / \mathrm{dl} \pm 5.13$ and prolactin level from $56.81 \mathrm{ng} / \mathrm{ml} \pm 31.86$ to $53.23 \mathrm{ng} / \mathrm{ml} \pm 37.63$. However these differences were not statistically significant $(\mathrm{p}>0.05)$, using the un-paired t-test.

Table 2 shows the analysis of significant difference between the pre-and post TENS application pain level on the VAS pain scale using the Wilcoxon Signed Ranks Test. There was a significant reduction $(\mathrm{p}<0.05)$ in the pain levels of the subjects from a value of $5.5 \pm 1.7$ to $1.5 \pm 2.1$ post TENS application.

\section{DISCUSSION}

It was observed in this study that there was a slight reduction in the mean values of cortisol and prolactin post-treatment, but the differences were not statistically significant $(\mathrm{p}>0.05)$. This agrees with the study of Rodriguez et al, (1992) who reported similar results in women with postoperative pain following hysterectomy.

Table 1: Analysis of Pre and Post TENS Therapy Cortisol and Prolactin levels using the paired t-Test.

\begin{tabular}{lllll}
\hline $\mathbf{N}=\mathbf{2 1}$ & PRE-TENS & POST-TENS & t & p-value \\
& $\mathbf{X} \pm$ SD & $\mathbf{X} \pm$ SD & & \\
\hline Cortisol & $28.45 \pm 5.27 \mathrm{ig} / \mathrm{dL}$ & $27.33 \pm 5.13 \mathrm{ig} / \mathrm{dL}$ & 1.042 & 0.310 \\
Prolactin & $56.81 \pm 31.86 \mathrm{ng} / \mathrm{mL}$ & $53.23 \pm 37.63 \mathrm{ng} / \mathrm{mL}$ & 0.639 & 0.530 \\
\hline
\end{tabular}

Table 2: Analysis of Pre and Post TENS Therapy Pain level Using Wilcoxon Signed Ranks Test.

\begin{tabular}{lcll}
\hline Pre-TENS VAS & Post-TENS VAS & Z & P-value \\
\hline $5.50 \pm 1.73$ & $1.50 \pm 2.08$ & -3.409 & $0.001 *(\mathrm{p}<0.05)$ \\
\hline
\end{tabular}

The reason for the lack of significant difference in cortisol and prolactin levels may have been attributed to the small sample size and also perhaps, if blood samples had been obtained during the TENS treatment, changes in cortisol and prolactin levels might have reveal a significant differences as suggested by the study of Kaplan et al, (1994).

Al-Damluji and Gaillard, (1987), asserted that the novelty and unpredictability of an acute 
situation is an important determinant of the degree of adrenocortical responsiveness. Although the subjects in this study were aware of the experimental procedure and the discomfort of venepuncture, all the subjects had never used TENS prior to this study. Thus the experimental procedure and treatment may have represented a stressor sufficient to elicit an elevation in pretreatment cortisol and prolactin levels of subjects (Al-Damluji and Gaillard 1987; Denegar et al, 1989). This study also showed a reduction in the mean post-treatment prolactin levels though the difference was not significant. This result supports the study of Rodriguez et al, (1992) who recorded slightly lower concentration of prolactin in response to high frequency TENS in hysterectomized women with post-operative pain.

The fact that women experienced significant reduction in pain levels is in agreement with the commonly seen trend in the literature concerning TENS as an analgesic agent in some painful conditions (Akin et al, 2001; Proctor et al, 2002). The ability of highfrequency TENS to achieve this reduction in pain level may be explained by its effect on the Opioid-Modulating Analgesia System (OMAS). Application of TENS stimulates release of endogenous opiates (like B-endorphin) which produce analgesia (Hughes et al, 1984). Apart from modulating pain, B-endorphin also exhibits close relationship with cortisol and prolactin (Dent et al, 1981; Plosker et al, 1990). Bendorphin shares a common precursor with ACTH, and ACTH regulates cortisol secretion (Plosker et al, 1990). B-endorphin also lies in close proximity to neurons which secrete dopamine into the hypothalamic - pituitary portal system. Thus, the modulation of dopamine by B-endorphin indirectly regulates prolactin secretion (Plosker et al, 1990). The mean menstrual phase cortisol and prolactin levels in this study were above normal range for premenopausal women. This result is contrary to the study of Baker et al, (1999), who reported that only in the luteal phase was the mean prolactin secretion for dysmenorrhoeics subjects is above the normal range.

\section{CONCLUSION}

This study concluded that high frequency TENS significantly reduced the pain levels in dysmenorrhoeic women without significantly affecting serum levels of cortisol and prolactin level.

The study also gives further evidence that women with PD have disturbed hormonal status.

\section{REFERENCES}

- Akin MD, Weingand KW, Hengehold DA, Goodale MB, Hinkle RT, Smith RP (2001). Continous lowlevel topical heat in the treatment of dysmenorrhoea. Obstetrics and Gynecology, 97 (3): 343-349.

- Al-Damluji S, Gaillard RC (1987). Stress and the pituitary- adrenal axis. Ballieres Clinical Endocrinology and Metabolism, 1 (2): 319-354.

- Andersch B, Milson I. (1982). An epidemiologic study of young women with dysmenorrhoea. American Journal of Obstetrics and Gynecology, 144 (6): 665660.

- Baker FC, Driver HS, Rogers GG, Paiker J, Mitchell D (1999). High nocturnal body temperature and disturbed sleep in women with primary dysmenorrhoea. American Journal of Physiology Endocrinology and Metabolism, 277 (6): 1013-1021.

- Chan WY and Dawood MY (1980). Prostaglandin levels in menstrual fluid of nondysmenorrhoeic and of dysmenorrhoeic subjects with and without oral contraceptive or ibuprofen therapy. Advances in Prostaglandin and Thromboxane Research, 8: 14431447.

- Dawood MY, Ramos J (1990). Transcutaneous electrical nerve stimulation (TENS) for the treatment of primary dysmenorrhoea. A randomized crossover comparison with placebo TENS and Ibuprofen. Obstetrics and Gynecology, 75 (4): 656-660.

- De Cree C (1989). Endogenous opiod peptides in the control of the normal menstrual cycle and their psible role in athletic menstrual irregularities. Obstetric and Gynecological Survey, 44 (10): 720-732.

- Denegar CR, Perrin DH, Rogol AD, Rutt R (1989): Influence of transcutaneous electrical nerve stimulation

on pain, range of motion, and serum cortisol concentration in females experiencing delayed onset muscle soreness. Journal of JOrthopaedic and Sports Physical Therapy, 11 (3): 100-103.

- Dent RRM, Guilleminault C, Albert LH, Posner BI, Cox BM, Goldstein A (1981). Diurnal rhythm of plasma immunoreactive B-endorphin and its relationship to sleep stages and plasma rhythms of cortisol and prolactin. Journal of Clinical Endocrinology and Metabolism, 52 (1): 942-947.

- Flower RJ, Vane JR (1974). Inhibition of prostaglandin biosynthesis. Biochemical Pharmacy, 23: $1439-1450$.

- Ganong WF (2001). Review of Medical Physiology $\left(20^{\text {th }}\right.$ ed) $(350,408-410,419-422)$. New York: McGraw-Hill.

- Henzl MR, Massey S, Hanson FW, Buttran VC, Rosenwaks Z, Pauls FD (1998). Primary dysmenorrhoea. The therapeutic challenge. Journal of Reproductive Medicine, 25: 226-235. 
- Hughes GS, Lichstein PR, Witlock D, Harker C (1984). Response of plasma beta-endorphins to transcutaneous electrical nerve stimulation in healthy subjects. Physical Therapy, 64: 1062-1066.

- Kaplan B, Peled Y, Pardo J, Rubinerson D, Hirsh M, Ovadia J, Neri A (1994). Transcutaneous electrical nerve stimulation (TENS) as a relief for dysmenorrhoea. Clinical and Experimental Obstetrics and Gynecology, 21 (2): 87-90.

- Langrick AF, Gunn ADG, Livesey H, Whitehead AM (1989). A double blind placebo-controlled crossover study of mebeverine and mefenamic acid in the treatment of primary dysmenorrhoea. British Journal of Clinical practice, 43 (9): 317-321.

- Lewers D, Clelland JA, Jackson JR, Varner RE, Bergman J. (1989). Transcutaneous electrical nerve stimulation in the relief of primary dysmenorrhoea. Physical Therapy, 69 (1): 17-23.

- Lin L. (1998). Literature research on point injection with Chinese Angelica liquor. Journal of Traditional Chinese Medicine, 18: 308-312.

- Lundeberg T, Bondesson L and Lundstrom V (1985). Relief of primary dysmenorrhoea by transcutaneous electrical nerve stimulation. Acta Obstetricia et Gynecologica Scandinavica, 64 (6): 491-497.

- Manheimer Js, Whalen EC (1985). The efficacy of TENS in dysmenorrhoea. Clinical Journal of Pain, 1: 75-83.

- Mattews AEB, Clarke JEF (1968). Double-blind trial of a sequential oral contraceptive (sequens) in the treatment of dysmenorrhoea Journal of Obstetrics and Gynaecology British Commonwealth, 75: 1117-1122.

- Menaker JS, Powers KD (1962). Management of primary dysmenorrhoea. Obstetrics and Gynecology, 20: $66-71$.

- Orth DN, Kovacs WJ \& De Bold RC(1992). The adrenal corex. In Wilson JD, Foster DW (Eds)
Williams Textbok of Endocrinology ( $8^{\text {th }}$ Ed) (pp 489619). Philadelphia: WB Saunders.

- Plosker SM, Marshall LA, Martin MC, Jaffe RB (1990). Opioid, cathechlamine, and steroid interaction in prolactin and gonadotropin regulation. Obstetric and Gynecological Survey, 45 (7): 441-453.

- Proctor ML, Hing W, Johnson TC, Murphy PA (2004). Spinal manipulation for primary and secondary dysmenorrheoa (Cochrane Review). The Cochrane Library, Issue 3. Chichester: John Wiley and Sons.

- Pulkkinen M (1979). Suppression of uterine activity by prostaglandin synthetase inhibitors. Acta Obstetricia \& Gynecologica Scandinavica, 87 (Suppl): 39-43.

- Rodriguez E, Meizoso MJ, Garabal M, Fernandez MP, Rodriquez-Bujan L, Belmonte A (1992), Effects of transcutaneous nerve stimulation on the plasma concentrations of ACTH, cortisol and prolactin in hysterectomized women with post-operative pain. Revista Espanola De Anestesiologia Y Reanimacion (Barcelona) 39 (1): 6-9.

- Smith RP (1993). Cyclic pelvic pain and dysmenorrhoea. Obstetrics and Gynecology Clinics of North America, 20 (4): 753-764.

- Stromberg P, Forsling ML and Akerlund M (1981). Effects of prostaglandin inhibition on vasopression levels in women with primary dysmenorrhoea. Obstetrics and Gynecology, 58 (2): 206-208.

- Yuqin (1994). A report of 49 cases of dysmenorrhoea treated by acupuncture. Journal of Traditional Chinese Medicine, 4: 101-102.

- Zhang WY, Li Wan Po A (1998). Efficacy of minor analgesics primary dysmenorrhoea: a systemic review. British Journal of Obstetrics and Gynaecology, 105: 780-789. 